\title{
COMPOSIÇÃO FÍSICO-QUÍMICA DO VINHO CABERNET FRANC PROVENIENTE DE VIDEIRAS CONDUZIDAS NO SISTEMA LIRA ABERTA ${ }^{1}$
}

\author{
Luciano MANFROI ${ }^{2, *}$, Alberto MIELE ${ }^{3}$, Luiz A. RIZZON ${ }^{3}$, Carlos I.N. BARRADAS ${ }^{4}$
}

\section{RESUMO}

O objetivo do trabalho foi avaliar as características físico-químicas do vinho Cabernet Franc proveniente de videiras conduzidas no sistema lira aberta durante o ciclo vegetativo de 1995/1996. O experimento foi realizado em oito vinhedos localizados nos municípios de Bento Gonçalves e Monte Belo do Sul, Estado do Rio Grande do Sul. Os vinhos foram elaborados por microvinificação, com duas repetições para cada vinhedo, os quais foram analisados por processos físico-químicos, espectrofotometria de absorção atômica e cromatografia líquida e gasosa. Os parâmetros das variáveis mais significativas foram os seguintes: álcool 9,65\%, acidez total 69 meq L ${ }^{-1}$, pH 3,46, extrato seco reduzido $16,0 \mathrm{~g} \mathrm{~L}^{-1}$, K nas cinzas 49,4\%, ácido tartárico $33 \mathrm{meq} \mathrm{L}^{-1}$, glicerol 9,3 g L $\mathrm{L}^{-1}$, prolina $669 \mathrm{mg} \mathrm{L}^{-1}$, antocianinas $330 \mathrm{mg} \mathrm{L}^{-1}$, taninos $1,19 \mathrm{~g} \mathrm{~L}^{-1}$, intensidade de cor 0,286, $\mathrm{K} 1.078 \mathrm{mg} \mathrm{L}^{-1}$, metanol $101,7 \mathrm{mg} \mathrm{L}^{-1} \mathrm{e} \mathrm{soma}^{-1}$ dos álcoois superiores $450 \mathrm{mg} \mathrm{L}^{-1}$. Os resultados dos vinhos avaliados foram relativamente similares aos encontrados em vinhos Cabernet Franc da mesma região elaborados com uvas provenientes de videiras conduzidas em latada. Eles evidenciam que o sistema de condução da videira em lira aberta constitui-se como alternativa para a produção de vinho tinto fino na Serra Gaúcha.

Palavras-chave: enologia, composição química, vinho, Cabernet Franc, sistema de condução.

\section{SUMMARY}

PHYSICO-CHEMICAL COMPOSITION OF CABERNET FRANC WINE FROM VINEYARDS CONDUCTED IN THE LYRE SYSTEM. The objective of the work was to evaluate the physico-chemical characteristics of the Cabernet Franc wine from the 1995/1996 vegetative cycle. It was conducted in eight vineyards in the communes of Bento Gonçalves and Monte Belo do Sul, State of Rio Grande do Sul, Brazil. From each vineyard, two microvinifications were elaborated and wines were analysed by physicochemical, atomic absorption spetrophotometry, and liquid and gas chromatography processes. The parameters of the most significant variables

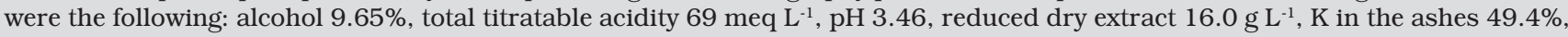
tartaric acid $33 \mathrm{meq} \mathrm{L}^{-1}$, glycerol $9,3 \mathrm{~g} \mathrm{~L}^{-1}$, proline $669 \mathrm{mg} \mathrm{L}^{-1}$, anthocyanins $330 \mathrm{mg} \mathrm{L}^{-1}$, tannins $1.19 \mathrm{~g} \mathrm{~L}^{-1}$, color intensity 0.286 , $\mathrm{K} 1,078 \mathrm{mg} \mathrm{L}^{-1}$, methanol $101.7 \mathrm{mg} \mathrm{L}^{-1}$, and summ of higher alcohols $450 \mathrm{mg} \mathrm{L}^{-1}$. The results found in the analysed wines showed similar results to parameters previously determined in Cabernet Franc wine from the same region elaborated from grapes cultivated in the pergola system. This makes evident that grapevines conducted in the lyre system are an alternative to produce quality red wine in the Serra Gaúcha region.

Keywords: enology, chemical composition, wine, Cabernet Franc, trellising system.

\section{1 - INTRODUÇÃO}

Nos últimos anos, tem havido um grande esforço da pesquisa buscando relacionar os efeitos do sistema de condução sobre a videira, tais como a ecofisiologia e o regime hídrico [8, 37] e a qualidade do vinho [5, 6, 16].

O tipo de solo, variações do clima e algumas práticas culturais, como a condução da videira, podem afetar a qualidade do vinho [35]. Dependendo do sistema de condução empregado, as práticas culturais estimulam o crescimento e o desenvolvimento da videira, marcando os

\footnotetext{
${ }^{1}$ Recebido para publicação em 3/12/2004. Aceito para publicação em 28/04/2006 (001450)

${ }^{1}$ Parte da dissertação de mestrado em Fitotecnia apresentada pelo primeiro autor ao curso de pós-graduação em Agronomia (UFRGS), Porto Alegre (RS)

${ }^{2}$ Centro Federal de Educação Tecnológica de Petrolina, Rua Amadeu C. Cavalcante, 75, CEP 56310-658 - Petrolina (PE). E-mail:Imanfroi@bol.com.br

${ }^{3}$ Embrapa Uva e Vinho, Caixa Postal 130, CEP 95700-000 - Bento Gonçalves (RS).E-mails:miele@cnpuv.embrapa.br; rizzon@cnpuv.embrapa.br ${ }^{4}$ Professor aposentado do Departamento de Horticultura e Silvicultura da Universidade Federal do Rio Grande do Sul, Porto Alegre (RS)

*A quem a correspondência deve ser enviada
}

efeitos no microclima do dossel vegetativo [33]. LOWE [18] observou que utilizando um manejo adequado do dossel vegetativo, houve aumento da produção de uva e melhoria na qualidade do vinho, expressa pelo aumento da cor, do teor de taninos e do aroma.

Segundo SMART et al. [36] e SMART [33], o sombreamento tem seu maior efeito na composição final do fruto. Sombreamento no início da maturação reduz a concentração de açúcar no fruto, a relação glicose/frutose e os teores de polifenóis e de antocianinas. Por outro lado, ocorre aumento na concentração dos minerais N, K, Ca e Mg e no $\mathrm{pH}$, sendo este aumento diretamente proporcional ao aumento do sombreamento causado pelo excesso de folhas do dossel vegetativo. Uma adequada exposição dos frutos à radiação solar é fator determinante para a melhoria da composição da uva e do potencial qualitativo do vinho [22, 34]. A acumulação de polifenóis e a qualidade aromática da uva são fortemente atribuídas ao microclima das folhas e dos cachos, e isto está na dependência do equilíbrio da superfície foliar do dossel vegetativo [7].

O sistema de condução em lira melhora a maturação da uva e a qualidade do vinho, favorecendo teores 
adequados de pH, açúcares, etanol e aroma [5, 7] e de compostos fenólicos [17]. A acumulação de polifenóis e a qualidade aromática da uva são fortemente atribuídas ao microclima das folhas e dos cachos, e isto está na dependência do equilíbrio da superfície foliar do dossel vegetativo [6]. Além disso, trabalhos realizados por CARBONNEAU [7] mostram que os vinhos obtidos de vinhedos conduzidos em lira aberta foram superiores nas notas aromáticas.

Os componentes inorgânicos da videira e da uva têm significativa importância na qualidade do vinho. A concentração e as substâncias que compõem os frutos são influenciadas por vários fatores, como a maturação, a cultivar, a época do ano, as práticas culturais e as condições climáticas. No vinho, além desses fatores há o efeito do processo de vinificação [40].

Em função do que foi discutido acima, o presente trabalho teve por objetivo caracterizar a composição físico-química do vinho Cabernet Franc obtido de videiras conduzidas no sistema lira aberta na principal região vitivinícola do País, a Serra Gaúcha, podendo se constituir numa alternativa ao tradicional sistema latada.

\section{2 - MATERIAL E MÉTODOS}

O trabalho foi realizado no ciclo vegetativo de 1995/1996, em oito vinhedos de Cabernet Franc (Vitis vinifera L.), localizados nos municípios de Bento Gonçalves (comunidades de São Valentim, Tuiuti e Pinto Bandeira) e de Monte Belo do Sul, ambos no Rio Grande do Sul.

Os vinhedos foram instalados em 1989 e conduzidos no sistema lira aberta. Este sistema se caracteriza pela condução das videiras em dois planos oblíquos, mantidos por três fios em cada um dos planos. O espaçamento variou de 1,00 a 1,35 m entre as plantas e de 2,50 a 3,10 m entre as fileiras. A poda seca foi mista, deixando-se em média 4,3 varas/planta com 5,3 gemas/vara; e 11,9 esporões/planta com 1,3 gema/esporão, ou seja, 38,3 gemas/planta.

Por ocasião da maturação, colheram-se aproximadamente $2 \mathrm{~kg}$ de uva/planta, totalizando $40 \mathrm{~kg} /$ vinhedo, os quais foram posteriormente microvinificados com duas repetições. A uva esmagada foi colocada em recipientes de vidro com capacidade de $20 \mathrm{~L}$, acrescentando-se $50 \mathrm{mg} \mathrm{SO} / 2 \mathrm{~kg}$ de uva e leveduras liofilizadas Saccharomyces cereviseae (200 mg/kg de uva). Os recipientes foram fechados com válvulas de Müller, não permitindo contato do ar com o mosto em fermentação. A seguir, foram colocados numa sala com temperatura controlada de aproximadamente $25^{\circ} \mathrm{C}$.

Após seis dias de maceração, fez-se a descuba prensando-se o bagaço. Depois de 15 dias, foi realizada a trasfega, separando a borra e colocando o vinho em recipientes de 5 L. Após o término da fermentação malolática, verificada por cromatografia de papel, estabilizaram-se os vinhos pelo frio $\left(-4^{\circ} \mathrm{C}\right)$ por um período de 10 dias, ao final do qual foram filtrados e engarrafados.
Os vinhos foram, então, analisados nos laboratórios de Enoquímica e de Cromatografia da Embrapa Uva e Vinho. A densidade foi determinada através de um densímetro digital marca Anton Paar, modelo DMA-45; o álcool, determinado com um refratômetro de imersão [19]; a acidez total, pela titulação do vinho com $\mathrm{NaOH}$ 0,1 N, utilizando o azul de bromotimol como indicador; a acidez volátil, pelo arraste de vapor com titulação do vinho com $\mathrm{NaOH}$ 0,1 N e fenolftaleína como indicador; e o pH, com um potenciômetro digital, marca Corning, modelo 125, equipado com eletrodo de vidro e calibrado com solução padrão de pH 3,0 e pH 4,0.

Os açúcares redutores foram determinados segundo metodologia de MEYER \& LEYGUE-ALBA [ 19]; o extrato seco e o extrato seco reduzido, segundo RIBÉREAU-GAYON et al. [24]; as cinzas, pela incineração de $20 \mathrm{~mL}$ de vinho em cadinhos de platina a $530-550^{\circ} \mathrm{C}$ [1]; a alcalinidade das cinzas, segundo USSEGLIO-TOMASSET [39]; os cloretos, conforme AMERINE \& OUGH [1]; a prolina, segundo metodologia de GIANNESSI \& MATTA [15]; as antocianinas, segundo RIBÉREAU-GAYON \& STONESTREET [26]; os taninos, conforme RIBÉREAU-GAYON \& STONESTREET [25]; os polifenóis totais, medindo-se a absorbância através de espectrofotômetro UV/VIS a 280 nm [24]; os índices 420 e 520, medindo-se a absorbância com espectrofotômetro a 420 e 520 nm [23]; e o ácido tartárico, através de cromatografia líquida de alta performance [2].

A determinação da maioria dos minerais foi realizada por um espectrofotômetro de absorção atômica PerkinElmer, modelo 2380, equipado com lâmpadas de cátodo oco para cada elemento. O Ca, Mg, Mn, Zn, Cu e Fe foram determinados por absorção atômica e o K, Na, Li e Rb, por emissão de chama [21]. Para a determinação do N e do P, utilizou-se a metodologia proposta por TEDESCO et al.[38], adaptada para mostos e vinhos.

A análise dos compostos voláteis foi realizada de acordo com a metodologia de BERTRAND [3], utilizando um cromatógrafo a gás, marca CG Instrumentos Científicos, modelo 3537-S, equipado com detector de ionização de chama. A coluna utilizada foi a empacotada CG5912 "Carbowax 400 + Hallcomid M-18-OL", de aço inoxidável, $5 \mathrm{~m}$ de comprimento e 1/8" de diâmetro. Utilizou-se o 4-metil-2-pentanol como padrão interno. O glicerol também foi determinado por cromatografia gasosa com o mesmo aparelho que se determinaram os compostos voláteis. Neste caso, o detector foi o de ionização de chama, a coluna foi empacotada, de aço inoxidável, 2 m de comprimento e 3/4" de diâmetro, com Tenax. O padrão interno utilizado foi o 1,6-hexanodiol [4].

\section{3 - RESULTADOS E DISCUSSÃO}

Os resultados das análises físico-químicas do vinho Cabernet Franc estão indicados na Tabela 1. A densidade está relacionada com o teor alcoólico e os açúcares redutores do vinho, sendo que os valores mínimo e máximo encontrados neste trabalho foram de 0,9946 e 0,9958 $\mathrm{g} \mathrm{mL}^{-1}$, 
respectivamente, e a concentração média de álcool foi de $9,65 \%(v / v)$. Apesar de não ter sido realizada a chaptalização, estes resultados indicam uma maturação similar à média da Serra Gaúcha para a cv. Cabernet Franc, mesmo que as condições climáticas não tenham sido ideais. Os açúcares redutores que não foram transformadas em álcool durante a fermentação alcoólica, apresentaram concentração média de $2,07 \mathrm{~g} \mathrm{~L}^{-1}$, permanecendo dentro dos valores estabelecidos pela legislação brasileira para vinhos secos.

A acidez total média foi de 69 meq $\mathrm{L}^{-1}$, reforçando a idéia de que as condições climáticas ao final da maturação não contribuíram para baixá-la. A acidez total no vinho em relação à do mosto foi reduzida aproximadamente à metade, como conseqüência da precipitação do tartarato ácido de potássio durante a refrigeração e pela redução do ácido málico durante a fermentação malolática. O valor médio da acidez volátil foi de $6,5 \mathrm{meq} \mathrm{L}^{-1}$, semelhante ao encontrado por RIZZON \& MIELE [30], o que indica uma correta condução das fermentações alcoólica e malolática. Estes valores são considerados adequados para vinhos tintos bem elaborados. $\mathrm{O} \mathrm{pH}$ médio do vinho foi de 3,46 . O aumento do $\mathrm{pH}$ do vinho em relação ao mosto está diretamente relacionado com a precipitação do ácido tartárico durante o tratamento físico pelo frio. O pH é importante pelo seu efeito na cor, no sabor e na proporção entre $\mathrm{SO}_{2}$ livre e combinado. Para que o vinho atinja níveis satisfatórios destas características, o $\mathrm{pH}$ deve ficar entre 3,1 e 3,6 [1].

O extrato seco médio foi de $17,1 \mathrm{~g} \mathrm{~L}^{-1}$. Os baixos teores de extrato seco são função direta da relação entre a fase

TABELA 1 - Composição físico-química do vinho Cabernet Franc proveniente de videiras conduzidas no sistema lira aberta. Bento Gonçalves e Monte Belo do Sul (RS). Safra 1995/1996

\begin{tabular}{|c|c|c|c|c|c|c|}
\hline Vinhedo & $\begin{array}{c}\text { Densidade relativa } \\
\left(20 / 20^{\circ} \mathrm{C}\right)\end{array}$ & $\begin{array}{c}\text { Álcool (\%v/v) } \\
20^{\circ} \mathrm{C}\end{array}$ & $\begin{array}{l}\text { Acidez total } \\
\left(\text { meq } L^{-1}\right)\end{array}$ & $\begin{array}{l}\text { Acidez volátil } \\
\left.\text { (meq L }{ }^{-1}\right)\end{array}$ & $\mathrm{pH}$ & $\begin{array}{c}\text { Açúcares redutores } \\
\left(\mathrm{g} \mathrm{L}^{-1}\right)\end{array}$ \\
\hline Vinhedo 1 & 0,9946 & 10,35 & 79 & 5,5 & 3,52 & 2,10 \\
\hline Vinhedo 2 & 0,9950 & 9,99 & 68 & 6,4 & 3,51 & 2,29 \\
\hline Vinhedo 3 & 0,9950 & 9,59 & 65 & 5,1 & 3,52 & 1,97 \\
\hline Vinhedo 4 & 0,9954 & 9,16 & 68 & 6,5 & 3,44 & 1,92 \\
\hline Vinhedo 5 & 0,9949 & 9,89 & 70 & 6,7 & 3,32 & 2,24 \\
\hline Vinhedo 6 & 0,9946 & 9,99 & 64 & 6,3 & 3,40 & 2,21 \\
\hline Vinhedo 7 & 0,9955 & 9,54 & 76 & 7,5 & 3,42 & 2,24 \\
\hline Vinhedo 8 & 0,9958 & 8,68 & 63 & 7,6 & 3,57 & 1,62 \\
\hline MÉDIA & 0,9951 & 9,65 & 69 & 6,5 & 3,46 & 2,07 \\
\hline CV(\%) & 0,04 & 5,49 & 5,76 & 13,49 & 2,31 & 11,11 \\
\hline
\end{tabular}

\begin{tabular}{|c|c|c|c|c|c|c|c|}
\hline Vinhedo & $\begin{array}{l}\text { Extrato seco } \\
\qquad\left(\mathrm{g} \mathrm{L}^{-1}\right)\end{array}$ & $\begin{array}{c}\text { Extrato seco } \\
\text { reduzido } \\
\left(\mathrm{g} \mathrm{L}^{-1}\right)\end{array}$ & $\begin{array}{c}\text { Álcool/ } \\
\text { Extrato seco }\end{array}$ & $\begin{array}{l}\text { Cinzas } \\
\left(g^{-1} L^{-1}\right.\end{array}$ & $\begin{array}{c}\text { Alcalinidade } \\
\text { das cinzas } \\
\left(\text { meq L-1) }^{-1}\right.\end{array}$ & $\begin{array}{l}\text { Alcalinidade das } \\
\text { cinzas/ Cinzas }\end{array}$ & $\begin{array}{l}\text { Extrato seco } \\
\text { reduzido/Cinzas }\end{array}$ \\
\hline Vinhedo 1 & 18,2 & 17,1 & 4,86 & 2,48 & 23,2 & 9,35 & 6,90 \\
\hline Vinhedo 2 & 17,8 & 16,5 & 4,84 & 2,13 & 21,2 & 9,95 & 7,75 \\
\hline Vinhedo 3 & 16,8 & 15,8 & 4,84 & 2,20 & 21,8 & 9,91 & 7,20 \\
\hline Vinhedo 4 & 15,8 & 14,9 & 4,92 & 2,15 & 20,2 & 9,40 & 6,93 \\
\hline Vinhedo 5 & 17,6 & 16,4 & 4,84 & 1,80 & 17,4 & 9,67 & 9,09 \\
\hline Vinhedo 6 & 17,0 & 15,8 & 5,06 & 2,13 & 20,6 & 9,67 & 7,42 \\
\hline Vinhedo 7 & 17,4 & 16,2 & 4,72 & 2,15 & 21,4 & 9,95 & 7,52 \\
\hline Vinhedo 8 & 16,2 & 15,6 & 4,46 & 2,40 & 22,2 & 9,25 & 6,50 \\
\hline MÉDIA & 17,1 & 16,0 & 4,82 & 2,18 & 21,0 & 9,64 & 7,41 \\
\hline CV(\%) & 4,74 & 4,12 & 3,53 & 9,17 & 8,24 & 2,90 & 10,53 \\
\hline
\end{tabular}

\begin{tabular}{|c|c|c|c|c|c|c|c|c|}
\hline Vinhedo & $\begin{array}{c}\text { K nas cinzas } \\
(\%)\end{array}$ & $\begin{array}{l}\text { Ácido tartárico } \\
\left.\text { (meq } \mathrm{L}^{-1}\right)\end{array}$ & $\begin{array}{l}\text { Ácido tartárico/ } \\
\text { Acidez fixa }\end{array}$ & $\begin{array}{c}\text { Dióxido de } \\
\text { enxofre total } \\
\left(\mathrm{mg} \mathrm{L}^{-1}\right)\end{array}$ & $\begin{array}{l}\text { Dióxido de } \\
\text { enxofre livre } \\
\left(\mathrm{mg} \mathrm{L}^{-1}\right)\end{array}$ & $\begin{array}{l}\text { Cloretos } \\
\left(\mathrm{mg} \mathrm{L}^{-1}\right)\end{array}$ & $\begin{array}{l}\text { Glicerol } \\
\left(\mathrm{mg} \mathrm{L}^{-1}\right)\end{array}$ & $\begin{array}{l}\text { Prolina } \\
\left(\mathrm{mg} \mathrm{L}^{-1}\right)\end{array}$ \\
\hline Vinhedo 1 & 49,3 & 32 & 0,44 & 72,3 & 34,6 & 10,5 & 10,5 & 189 \\
\hline Vinhedo 2 & 52,1 & 29 & 0,47 & 86,4 & 42,2 & 8,2 & 10,0 & 679 \\
\hline Vinhedo 3 & 49,0 & 32 & 0,53 & 71,0 & 37,1 & 9,4 & 8,8 & 683 \\
\hline Vinhedo 4 & 49,4 & 33 & 0,54 & 66,6 & 40,3 & 10,5 & 8,6 & 661 \\
\hline Vinhedo 5 & 45,1 & 39 & 0,62 & 74,9 & 33,9 & 8,2 & 9,7 & 975 \\
\hline Vinhedo 6 & 48,8 & 35 & 0,61 & 67,2 & 31,4 & 11,0 & 9,5 & 581 \\
\hline Vinhedo 7 & 49,7 & 37 & 0,54 & 66,6 & 41,6 & 10,5 & 9,3 & 872 \\
\hline Vinhedo 8 & 51,5 & 28 & 0,51 & 51,2 & 32,0 & 5,8 & 8,3 & 714 \\
\hline MÉDIA & 49,4 & 33 & 0,53 & 69,5 & 36,6 & 9,3 & 9,3 & 669 \\
\hline CV(\%) & 4,28 & 11,35 & 11,32 & 14,20 & 11,64 & 9,11 & 7,93 & 34,60 \\
\hline
\end{tabular}


sólida (menor) e a líquida (maior) do mosto, que durante a execução deste trabalho sofreu influência do excesso de chuvas e do número de dias de maceração. Já o extrato seco reduzido, que é o extrato seco descontado do açúcar residual superior a $1 \mathrm{~g} \mathrm{~L}^{-1}$, foi de $16,0 \mathrm{~g} \mathrm{~L}^{-1}$. A relação álcool em peso/extrato seco reduzido foi, em média, de 4,82, ficando abaixo do máximo permitido pela legislação para os vinhos tintos, que é de 5,20.

A concentração média de cinzas foi de $2,18 \mathrm{~g} \mathrm{~L}^{-1}$. Normalmente, o valor das cinzas é de aproximadamente $10 \%$ do extrato seco, que neste caso foi de $13 \%$, confirmando os baixos valores de extrato seco e valores normais para as cinzas. A alcalinidade das cinzas foi, em média, de $21,0 \mathrm{meqL}^{-1}$. A alcalinidade das cinzas é uma medida da quantidade de sais de ácidos orgânicos presentes no mosto ou no vinho [1]. A relação alcalinidade das cinzas/cinzas variou entre 9,25 e 9,95 (média de 9,63), enquanto a média da relação extrato seco reduzido/cinzas variou de 6,50 a 9,09 (média de 7,41). Não foram encontrados registros de trabalhos que indicassem os valores destas variáveis para vinhos da Serra Gaúcha. O K contribuiu, em média, com 49,4\% do teor das cinzas, o que demonstra que é o cátion que participa com a maior proporção no mosto e no vinho.

O teor médio de ácido tartárico foi de $33 \mathrm{meq} \mathrm{L}^{-1}$. Este ácido orgânico, característico da uva, representa $50 \%$ ou mais da acidez total dos mostos e vinhos, informação constatada pelo resultado da relação ácido tartárico/acidez fixa, que variou de 0,44 a 0,62. O pH depende muito do ácido tartárico, e sua concentração diminui pela precipitação de tartarato ácido de potássio e de tartarato de cálcio, provocado pelo aumento do álcool e diminuição da temperatura.

A concentração média de dióxido de enxofre livre e total foi de $36,6 \mathrm{mg} \mathrm{L}^{-1}$ e $69,5 \mathrm{mg} \mathrm{L}^{-1}$, respectivamente. Estes valores indicam um bom equilíbrio na elaboração dos vinhos. As doses a empregar variam de acordo com o grau de maturação da uva, da sanidade, da temperatura, do teor de açúcar e, sobretudo, do $\mathrm{pH}$.

O valor médio de cloretos foi de $9,3 \mathrm{mg} \mathrm{L}^{-1}$, ocorrendo variações consideráveis que se situaram entre $5,8 \mathrm{mg} \mathrm{L}^{-1}$ e 11,0 mg L $\mathrm{m}^{-1}$. Os vinhos da Serra Gaúcha possuem baixos valores de cloretos porque os solos geralmente são argilosos e não apresentam problemas de salinidade.

A concentração média de glicerol foi de $9,3 \mathrm{~g} \mathrm{~L}^{-1}$, apresentando pequena variação entre os valores mínimo e máximo. A produção de glicerol é afetada pela concentração de açúcar, temperatura de fermentação, $\mathrm{pH}$, linhagem de levedura e quantidade de oxigênio presente. A concentração média de prolina foi de $669 \mathrm{mg} \mathrm{L}^{-1}$, com uma grande variação entre os valores mínimo ( $189 \mathrm{mg} \mathrm{L}^{-1}$ ) e máximo (975 $\mathrm{mg} \mathrm{L}^{-1}$ ), o que é explicado, em parte, pelos estágios de maturação dos diferentes vinhedos. O vinho Cabernet Franc caracteriza-se por apresentar altos teores de prolina.

Os compostos fenólicos e índices de cor estão descritos na Tabela 2. O valor médio das antocianinas foi de 330 $\mathrm{mg} \mathrm{L}^{-1}$, enquanto os vinhos tintos provenientes da Serra Gaúcha apresentam média ao redor de $145 \mathrm{mg} \mathrm{L}^{-1}$ [28, 29], bem abaixo, portanto, do encontrado neste trabalho. Os taninos variaram de $0,89 \mathrm{~g} \mathrm{~L}^{-1}$ a $1,78 \mathrm{~g} \mathrm{~L}^{-1}$. Como o trabalho foi conduzido por microvinificação, os valores ficaram relativamente baixos por não terem sido influenciados por temperaturas altas e excesso de remontagens.

A concentração de antocianinas aumenta rapidamente após a mudança de cor e é significativamente maior nas bagas expostas à luminosidade do que nas sombreadas. O valor médio de polifenóis totais foi de 27,5. A exposição dos cachos à radiação solar tem relação com o aumento da concentração de polifenóis presentes na uva, enquanto altas temperaturas têm sido correlacionadas com diminuição de seus teores [9].

O excesso de folhas em alguns vinhedos possivelmente contribuiu para baixar estes índices, juntamente com o tempo e a temperatura durante a maceração. Os valores médios dos índices 420 e 520 foram de 0,111 e 0,175 e o da intensidade de cor e da coloração de 0,286 e 0,65, respectivamente, abaixo dos encontrados por RIZZON \& MIELE [30]. O I 520 foi maior que o I 420, mostrando a predominância da cor vermelha sobre a amarela, o que caracteriza os vinhos jovens. Em relação à coloração, quanto mais envelhecido for o vinho mais a relação 420/520 aproxima-se de 1,0 devido à combinação entre os taninos e as antocianinas presentes no vinho.

TABELA 2 - Compostos fenólicos e índices de cor do vinho Cabernet Franc proveniente de videiras conduzidas no sistema lira aberta. Bento Gonçalves e Monte Belo do Sul, RS. Safra 1995/1996

\begin{tabular}{|c|c|c|c|c|c|c|c|}
\hline Vinhedo & $\begin{array}{c}\text { Antocianinas } \\
\left(\mathrm{mg} \mathrm{L}^{-1}\right)\end{array}$ & $\begin{array}{c}\text { Taninos } \\
\left(g^{-1}\right)\end{array}$ & $\begin{array}{l}\text { Polifenóis totais } \\
\qquad(1280)\end{array}$ & $\begin{array}{c}\text { Índice } \\
420\end{array}$ & $\begin{array}{c}\text { Índice } \\
520\end{array}$ & $\begin{array}{c}\text { Intensidade } \\
\text { de cor } \\
(1420+1520)\end{array}$ & $\begin{array}{l}\text { Coloração } \\
(1420 / 1520)\end{array}$ \\
\hline Vinhedo 1 & 405 & 1,78 & 32,1 & 0,155 & 0,270 & 0,425 & 0,58 \\
\hline Vinhedo 2 & 413 & 1,22 & 29,7 & 0,125 & 0,197 & 0,322 & 0,63 \\
\hline Vinhedo 3 & 324 & 1,06 & 24,9 & 0,099 & 0,153 & 0,252 & 0,65 \\
\hline Vinhedo 4 & 277 & 0,94 & 24,8 & 0,089 & 0,129 & 0,218 & 0,69 \\
\hline Vinhedo 5 & 317 & 1,17 & 27,8 & 0,122 & 0,202 & 0,323 & 0,60 \\
\hline Vinhedo 6 & 323 & 1,39 & 28,8 & 0,108 & 0,172 & 0,279 & 0,63 \\
\hline Vinhedo 7 & 347 & 1,08 & 28,5 & 0,103 & 0,168 & 0,271 & 0,61 \\
\hline Vinhedo 8 & 232 & 0,89 & 23,8 & 0,086 & 0,110 & 0,196 & 0,79 \\
\hline MÉDIA & 330 & 1,19 & 27,5 & 0,111 & 0,175 & 0,286 & 0,65 \\
\hline CV(\%) & 18,33 & 24,37 & 10,32 & 18,02 & 28,75 & 24,48 & 10,80 \\
\hline
\end{tabular}


Os minerais analisados estão indicados na Tabela 3. $\mathrm{O}$ valor médio de $\mathrm{N}$ total foi de $120 \mathrm{mg} \mathrm{L}^{-1}$. As maiores mudanças na composição química durante a fermentação do mosto, além da conversão do açúcar em etanol e glicerol, são o aumento de nitrogênio das células das leveduras e as perdas subseqüentes de nitrogênio total dos vinhos [1]. A média de $\mathrm{P}$ foi de $41,6 \mathrm{mg} \mathrm{L}^{-1}$, similar ao encontrado por RIZZON et al. [31]. O P aumenta com a maturação, podendo seus teores atingir de $50 \mathrm{mg} \mathrm{L}^{-1}$ a $150 \mathrm{mg} \mathrm{L}^{-1}$ na plena maturação [40].

A concentração média de $\mathrm{K}$ dos vinhos foi $1.078 \mathrm{mg}$ $\mathrm{L}^{-1}$, valor idêntico foi encontrado em pesquisas anteriores [28, 32]. O teor de K presente no vinho é função da cultivar, das condições climáticas durante seu desenvolvimento, da época de colheita, das temperaturas de fermentação e de armazenamento, da duração do armazenamento, do pH, da porcentagem de álcool e do equilíbrio iônico do vinho [1].

A concentração média de cálcio foi de $70,9 \mathrm{mg} \mathrm{L}^{-1}$, valor esperado já que a Serra Gaúcha caracteriza-se por apresentar baixos níveis de cálcio no solo e nos vinhos [28, 32]. O teor médio para o $\mathrm{Mg}$ foi de $65,7 \mathrm{mg} \mathrm{L}^{-1}$, valor inferior aos registrados por DAUDT \& GARCIA [12], cujos valores foram de 100,5 $\mathrm{mg} \mathrm{L}^{-1}$; por RIZZON \& SALVADOR [32], 85,3 $\mathrm{mg} \mathrm{L}^{-1}$; por RIZZON et al. [28], 81,3 $\mathrm{mg} \mathrm{L}^{-1}$. O Mg é um importante constituinte da videira, do mosto e do vinho. É encontrado em maior concentração nos vinhos tintos, devido a uma maior extração inicial e maior liberação do mineral para o mosto durante o período de maceração.

Quanto aos microelementos, o teor médio de $\mathrm{Na}$ foi de $2,5 \mathrm{mg} \mathrm{L}^{-1}$, pois as condições de umidade da região determinam baixos valores deste mineral nos mostos e vinhos. Comparando vinhos elaborados para fins de pesquisa e vinhos encontrados no comércio, diferenças muito grandes foram encontradas em relação ao Na. DAUDT \& GARCIA [12] encontraram 23,3 $\mathrm{mg} \mathrm{L}^{-1}$; RIZZON \& SALVADOR [32], 27,5 $\mathrm{mg} \mathrm{L}^{-1}$; e RIZZON et al. [28], 38,7 $\mathrm{mg} \mathrm{L}^{-1}$. Os teores registrados pela literatura estão compreendidos entre $20 \mathrm{mg} \mathrm{L}^{-1}$ e $200 \mathrm{mg} \mathrm{L}^{-1}$ [32].

O Fe encontrado no vinho foi, em média, de 1,2 mg $\mathrm{L}^{-1}$, abaixo do registrado por DAUDT \& GARCIA [12] e RIZZON et al. [28]. A concentração de Fe no vinho depende de sua concentração no solo e, também, da contaminação que ocorre durante a colheita, o transporte, o esmagamento e o engarrafamento.

A concentração de $\mathrm{Cu}$ no vinho, ao contrário do mosto, apresentou teor médio de $0,1 \mathrm{mg} \mathrm{L}^{-1}$. Isto ocorreu porque durante a fermentação alcoólica houve uma precipitação deste mineral através de sua fixação pelas leveduras e pelas borras e a precipitação na forma de sulfetos [20].

O teor médio de $\mathrm{Zn}$ no vinho foi de $0,1 \mathrm{mg} \mathrm{L}^{-1}$. Este mineral tem origem principalmente nos materiais, equipamentos e/ou recipientes vinários e nos tratamentos fitossanitários, podendo ainda ter origem biológica ou exógena a partir do solo e de várias outras fontes [11].

O valor médio do $\mathrm{Mn}$ foi de $1,9 \mathrm{mg} \mathrm{L}^{-1}$, abaixo do encontrado por RIZZON et al. [28]. A vinificação em tinto é responsável pelo aumento de teores deste elemento, uma vez que sua presença nas películas e nas sementes é elevada [13, 32]. As concentrações de Rb e de Li foram, em média, de 5,5 $\mathrm{mg} \mathrm{L}^{-1}$ e de 2,6 $\mu \mathrm{g} \mathrm{L}^{-1}$, respectivamente. A concentração de Li está de acordo com a mencionada pela literatura, podendo variar com o solo, a cultivar e a tecnologia de elaboração [31].

As concentrações de compostos voláteis e de glicerol do vinho Cabernet Franc são apresentadas na Tabela 4. A concentração média de acetato de etila foi de 53,1 mg L ${ }^{-1}$, indicando que a fermentação alcoólica transcorreu normalmente. Sua formação está ligada ao metabolismo das leveduras (fermentação), sobretudo de bactérias acéticas, ou à simples reações de esterificação que ocorrem durante os processos de maturação e envelhecimento dos vinhos [10].

Segundo RIZZON [27], valores elevados de acetato de etila proporcionam gosto acético nos vinhos, prejudicial, portanto, à sua qualidade. O acetato de etila representa aproximadamente $80 \%$ dos ésteres voláteis dos vinhos. O valor médio de metanol foi de $101,7 \mathrm{mg} \mathrm{L}^{-1}$. O metanol presente no vinho resulta da hidrólise das pectinas, o que explica sua grande dependência em função do processo de maceração das partes sólidas do cacho, em particular da película da uva.

O teor médio de 1-propanol encontrado foi de $13,8 \mathrm{mg} \mathrm{L}^{-1}$. Os teores deste álcool são dependentes do estado

TABELA 3 - Concentração dos minerais no vinho Cabernet Franc proveniente de videiras conduzidas no sistema lira aberta. Bento Gonçalves e Monte Belo do Sul (RS). Safra 1995/1996

\begin{tabular}{|c|c|c|c|c|c|c|c|c|c|c|c|c|}
\hline \multirow{2}{*}{ Vinhedos } & $\mathbf{N}$ & $\mathbf{P}$ & $K$ & $\mathrm{Ca}$ & $\mathrm{Mg}$ & $\mathrm{Na}$ & $\mathrm{Fe}$ & $\mathrm{Cu}$ & $\mathrm{Zn}$ & $\mathrm{Mn}$ & $\mathbf{R b}$ & \multirow{2}{*}{$\frac{\mathrm{Li}}{\mu \mathrm{g} \mathrm{L^{-1 }}}$} \\
\hline & & & & & & $\mathrm{mg} \mathrm{L}^{-1}$ & & & & & & \\
\hline Vinhedo 1 & 53 & 86,6 & 1.223 & 66,5 & 59,9 & 2,4 & 1,3 & 0,1 & 0,2 & 2,4 & 8,7 & 3,1 \\
\hline Vinhedo 2 & 114 & 24,6 & 1.109 & 79,0 & 64,1 & 2,4 & 1,3 & 0,1 & 0,1 & 2,1 & 6,0 & 3,5 \\
\hline Vinhedo 3 & 123 & 49,0 & 1.078 & 74,7 & 65,4 & 2,1 & 0,9 & 0,1 & 0,1 & 1,8 & 4,0 & 1,7 \\
\hline Vinhedo 4 & 123 & 39,6 & 1.061 & 68,8 & 68,6 & 2,1 & 1,1 & 0,1 & 0,1 & 1,9 & 5,6 & 0,9 \\
\hline Vinhedo 5 & 144 & 34,6 & 811 & 79,8 & 65,5 & 2,2 & 1,2 & 0,1 & 0,1 & 1,8 & 6,4 & 6,9 \\
\hline Vinhedo 6 & 105 & 35,8 & 1.039 & 71,9 & 71,9 & 2,5 & 1,3 & 0,1 & 0,1 & 2,7 & 5,4 & 2,1 \\
\hline Vinhedo 7 & 144 & 26,0 & 1.068 & 69,9 & 73,3 & 2,4 & 1,3 & 0,1 & 0,1 & 1,2 & 4,3 & 1,8 \\
\hline Vinhedo 8 & 153 & 36,6 & 1.237 & 56,6 & 57,0 & 3,6 & 1,2 & 0,2 & 0,2 & 1,1 & 3,4 & 1,1 \\
\hline MÉDIA & 120 & 41,6 & 1.078 & 70,9 & 65,7 & 2,5 & 1,2 & 0,1 & 0,1 & 1,9 & 5,5 & 2,6 \\
\hline CV (\%) & 26,39 & 47,43 & 12,17 & 10,52 & 8,46 & 19,51 & 13,22 & 36,36 & 38,46 & 28,72 & 30,47 & 73,50 \\
\hline
\end{tabular}


Composição físico-química do vinho Cabernet Franc, Manfroi et al.

TABELA 4 - Concentração de compostos voláteis e glicerol do vinho Cabernet Franc proveniente de videiras conduzidas no sistema lira aberta. Bento Gonçalves e Monte Belo do Sul (RS). Safra 1995/1996

\begin{tabular}{|c|c|c|c|c|c|c|c|}
\hline \multirow[t]{2}{*}{ Vinhedos } & $\begin{array}{c}\text { Acetato de } \\
\text { etila }\end{array}$ & Metanol & 1-propanol & $\begin{array}{c}\text { 2-metil- } \\
\text { 1-propanol }\end{array}$ & $\begin{array}{c}\text { 2-metil- } \\
\text { 1-butanol }\end{array}$ & $\begin{array}{c}\text { 3-metil- } \\
\text { 1-butanol }\end{array}$ & $\begin{array}{c}\text { Soma dos álcoois } \\
\text { superiores }\end{array}$ \\
\hline & \multicolumn{7}{|c|}{$\left(\mathrm{mg} \mathrm{L}^{-1}\right)$} \\
\hline Vinhedo 1 & 57,4 & 94,9 & 9,5 & 66,1 & 85,7 & 270,0 & 431,3 \\
\hline Vinhedo 2 & 52,9 & 140,5 & 14,7 & 100,5 & 93,2 & 315,6 & 524,0 \\
\hline Vinhedo 3 & 49,0 & 91,6 & 14,0 & 77,1 & 76,3 & 271,2 & 438,6 \\
\hline Vinhedo 4 & 45,3 & 95,3 & 14,8 & 90,3 & 72,1 & 255,1 & 432,3 \\
\hline Vinhedo 5 & 58,7 & 114,5 & 15,7 & 74,7 & 81,1 & 270,6 & 442,1 \\
\hline Vinhedo 6 & 52,0 & 97,3 & 11,0 & 80,6 & 83,2 & 277,3 & 452,1 \\
\hline Vinhedo 7 & 53,7 & 104,4 & 15,2 & 90,8 & 78,3 & 281,6 & 465,9 \\
\hline Vinhedo 8 & 55,7 & 75,3 & 15,6 & 92,6 & 64,1 & 244,9 & 417,2 \\
\hline MÉDIA & 53,1 & 101,7 & 13,8 & 84,1 & 79,3 & 273,3 & 450,4 \\
\hline CV(\%) & 8,31 & 18,88 & 16,65 & 13,47 & 11,14 & 7,62 & 7,35 \\
\hline
\end{tabular}

sanitário da uva e origina-se de fermentações bacterianas [14]. O 2-metil-1-propanol apresentou, em média, 84,1 mg $\mathrm{L}^{-1}$; o 2-metil-1-butanol, 79,3 $\mathrm{mg} \mathrm{L}^{-1}$; e o 3-metil-1-butanol, 273,3 $\mathrm{mg} \mathrm{L}^{-1}$. O 3-metil-1-butanol, segundo AMERINE \& OUGH [1], encontra-se em quantidades suficientes para influenciar significativamente as propriedades sensoriais do vinho. A média da soma dos álcoois superiores encontrada foi de $450,4 \mathrm{mg} \mathrm{L}^{-1}$.

\section{4 - CONCLUSÕES}

Os resultados das análises físico-químicas do vinho Cabernet Franc, elaborado com uvas produzidas no sistema de condução lira aberta de vinhedos instalados em diferentes áreas da Serra Gaúcha, apresentaram parâmetros similares aos vinhos tintos dessa região produzidos a partir de uvas de vinhedos conduzidos no tradicional sistema latada. Saliente-se, também, que esses parâmetros estão de acordo com a legislação brasileira. Os resultados obtidos evidenciam que o sistema de condução em lira pode ser recomendado para a produção de vinho tinto fino nas condições de clima e solo da Serra Gaúcha.

\section{5 - REFERÊNCIAS BIBLIOGRÁFICAS}

[1] AMERINE, M.A.; OUGH, C.S. Análisis de vinos y mostos. Zaragoza: Acribia, 1976, 158 p.

[2] AUGUSTE, M.H. Application de la chromatographie en phase liquide à haute pression à l'analyse des moûts et des vins. 1979, 135 p. Tese (doctorat en Oenologie-Ampélologie), Institut d’Oenologie, Université de Bordeaux II, Talence.

[3] BERTRAND, A. Recherches sur l'analyse des vins par chromatographie en phase gazeuse. 1975, $291 \mathrm{p}$. Tese (Doctorat d'Etat ès Sciences), Institut d'Oenologie, Université de Bordeaux II, Talence.

[4] CANTAGREL, R.; SYMONDS, P.; CARLES, J. Dosage du glycérol dans les vins par chromatographie en phase gazeuse. Revue Française d'Oenologie, n. 72, p. 37-39, 1978.

[5] CARBONNEAU, A. Conduite du vignoble et qualité du vin: des faux débats sur la densité de plantation à la "Lyriculture". Rivista di Viticoltura e di Enologia, v. 44 , n. 4 , p. 329-333, 1991a.
[6] CARBONNEAU, A. Étude écophysiologique des principaux systèmes de conduite. Intérêt qualitatif et économique des vignes en lyre. In: Simpósio Latino-americano de Viticultura e Enologia, 3.; Congresso Brasileiro de Viticultura e Enologia, 6.; Jornada Latino-americana de Viticultura e Enologia, 4., 1990, Bento Gonçalves e Garibaldi. Anais... Bento Gonçalves: Embrapa-CNPUV; ABTEV; OIV, 1991b, p. 21-34.

[7] CARBONNEAU, A. Influence des systèmes de conduite en "lyre" sur la physiologie de la vigne: bilan actuel et résultats de nouveaux essais. Le Progrès Agricole et Viticole, v. 99, n. 12, p. 290-299, 1982.

[8] CASTRO, R.; LOPES, C.; ALMEIDA, C.; AFONSO, J. Caractérisation écophysiologique de deux systémes de conduite de la vigne cv. Cabernet Sauvignon. Rivista di Viticoltura e di Enologia, v. 44, n. 4, p. 189-195, 1991.

[9] CRIPPEN JR., D.D.; MORRISON, J.C. The effects of sun exposure on the phenolic content of Cabernet Sauvignon berries during development. American Journal of Enology and Viticulture, v. 37, n. 4, p. 243-247, 1986.

[10] CURVELO-GARCIA, A.S. Controlo de qualidade dos vinhos. Odivelas: Pentaedro, 1988, 420 p.

[11] DAUDT, C.E.; DAL PIVA, G.C.; RIZZON, L.A. Minerais em mostos e vinhos oriundos de uvas tratadas com fungicida Dithane M-45. Boletim da sbCTA, v. 26, n. 2, p. 81-88, 1992.

[12] DAUDT, C.E.; GARCIA, N.G. Minerais em videiras, mostos e vinhos brasileiros. I - Minerais em vinhos. Ciência e Tecnologia de Alimentos, v. 7 , n. 1 , p. $72-81,1987$.

[13] DAUDT, C.E.; GARCIA, N.G.; RIZZON, L.A. Minerais em videiras, mostos e vinhos. II - Minerais em mostos, sua utilização durante a fermentação alcoólica e presença em vinhos. Ciência e Tecnologia de Alimentos, v. 7, n. 2, p. 189-204, 1987.

[14] DIRNINGER, N.; SCHAEFFER, A. Évolution des alcools supérieurs et du méthanol dans les eaux-de-vie de fruits produits dans le Nord-Est de la France. Cahier Scientifique, n. 126, p. 7-15, 1990.

[15] GIANNESSI, P.; MATTA, M. Trattato di scienza e tecnica enologica: Analisi e controllo dei mosti e dei vini. Brescia: $A E B, 1987$. v. 1, 349 p.

[16] IANNINI, B.; LAVEZZI, A.; TOMASI, D.; GIORGESSI, F. Effetti della densità di piantagione e della forma di allevamento sulla risposta quali-quantitativa di alcune 
cultivars dell'ambiente Laziale. Rivista di Viticoltura e di Enologia, v. 44, n. 4, p. 313-318, 1991.

[17] KATERJI, N.; DAUDET, F.A.; CARBONNEAU, A.; OLLAT, N. Étude à l'échelle de la plante entière du fonctionnement hydrique et photosynthétique de la vigne: comparaison des systèmes de conduite traditionnel et en lyre. Vitis, v. 33, n. 4, p. 197-203, 1994.

[18] LOWE, D. Canopy management - What is it? In: SMART, R.E.; ROBINSON, M.D., 1994. Sunlight into wine: a handbook for winegrape canopy management. $3^{\text {rd }}$. ed. Adelaide: Winetitles, 1994. p. 3.

[19] MEYER, C.R.; LEYGUE-ALBA, N.M.R. Manual de métodos analíticos enológicos. Caxias do Sul: UCS, $1991.51 \mathrm{p}$

[20] MIELE, A. Teores de manganês e de cobre no mosto das uvas 'Isabel' e 'Concord'. Pesquisa Agropecuária Brasileira, v. 22, n. 9/10, p. 897-901, 1987.

[21] PERKIN-ELMER. Analytical methods for atomic absorption espectrophotometry. Singapura: PerkinElmer, 2000. 300 p.

[22] REYNOLDS, A.G.; WARDLE, D.A. Impact of training system vines spacing on vine performance and berry composition of Seyval Blanc. American Journal of Enology and Viticulture, v. 45, n. 4, p. 444-451, 1994.

[23] RIBÉREAU-GAYON, J.; PEYNAUD, E.; RIBÉREAUGAYON, P.; SUDRAUD, P. Traité d'oenologie: sciences et techniques de vin. Paris: Dunod, 1976. v. 1, 671 p.

[24] RIBÉREAU-GAYON, J.; PEYNAUD, E.; RIBÉREAUGAYON, P; SUDRAUD, P. Traité d'oenologie: sciences et techniques de vin. Paris: Dunod, 1975. v. 2, 556 p.

[25] RIBÉREAU-GAYON, P.; STONESTREET, E. Dosage des tanins du vin rouge et détermination de leur structure. Chimie Analytique, v. 48, n. 4, p. 188-196, 1966.

[26] RIBÉREAU-GAYON, P.; STONESTREET, E. Le dosage des anthocianes dans le vin rouge. Bulletin de la Societé Chimique de France, v. 9, n. 419, p. 2.649-2.652, 1965.

[27] RIZZON, L.A. Composição química dos vinhos da microrregião homogênea vinicultora de Caxias do Sul (MRH 311) - Compostos voláteis. Bento Gonçalves: Embrapa-CNPUV, 1987. 4 p. (Comunicado Técnico, 5).

[28] RIZZON, L.A.; BIANCO, M.T.O.; REGINATTO, M.P.V.; FABIAN, V.; SALVADOR, M.B.G. Diferenciação analítica entre vinhos rosados e tintos da microrregião homogênea vinicultora de Caxias do Sul (MRH 311 ). Boletim da sbCTA, v. 26, n. 1, p. 6-12, 1992.
[29] RIZZON, L.A.; GATTO, N.M. Características analíticas dos vinhos da microrregião homogênea vinicultora de Caxias do Sul (MRH 311) - Análises Clássicas. Bento Gonçalves: Embrapa-CNPUV, 1987. 5 p. (Comunicado Técnico, 6).

[30] RIZZON, L.A.; MIELE, A. Avaliação da cv. Cabernet Franc para elaboração de vinho tinto. Ciência e Tecnologia de Alimentos, v. 21, n. 2, p. 249-255, 2001.

[31] RIZZON, L.A.; MIELE, A.; MENEGUZZO, J. Avaliação enológica de algumas cultivares de videira. Bento Gonçalves: Embrapa-CNPUV, 1986. 11 p. (PNP Vitivinicultura. Projeto 020.86.001/1).

[32] RIZZON, L.A.; SALVADOR, M.B.G. Teores de cátions dos vinhos da microrregião homogênea vinicultora de Caxias do Sul (MRH 311). Bento Gonçalves: Embrapa-CNPUV, 1987. 4 p. (Comunicado Técnico, 4).

[33] SMART, R.E. Principles of grapevine canopy microclimate manipulation with implications for yield and quality. A review. American Journal of Enology and Viticulture, v. 36, n. 3, p. 230-239, 1985.

[34] SMART, R.E.; ROBINSON, M.D. Sunlight into wine: A handbook for winegrape canopy management. $3^{\text {rd }}$. ed. Adelaide: Winetitles, 1994. 88 p.

[35] SMART, R.E.; ROBINSON, J.B.; DUE, G.R.; BRIEN, C.J. Canopy microclimate modification for the cultivar Shiraz. II. Effects on must and wine composition. Vitis, v. 24, n. 2, p. 119-128, 1985.

[36] SMART, R.E.; SMITH, S.M.; WINCHESTER, R.V. Light quality and quantity effects on fruit ripening for Cabernet Sauvignon. American Journal of Enology and Viticulture, v. 39, n. 3, p. 250-258, 1988.

[37] SOTTILE, I.; Di LORENZO, R.; OCCORSO, G.; BARBAGALLO, M.G.; BICA, D.; GERMANÀ, M.P.; NUCCIO, A. Confronto fra forme di allevamento, sistemi di potatura e densità di piantagione della vite in Sicilia: risultati preliminari. Rivista di Viticoltura e di Enologia, v. 44, n. 4, p. 119-131, 1991.

[38] TEDESCO, M.J.; GIANELLO, C.; BISSANI, C.A.; BOHEN, H.; VOLKWEISS, S.J. Análises de solo, plantas e outros materiais. $2^{\text {a }}$ ed. Porto Alegre: Departamento de Solos, Faculdade de Agronomia, UFRGS, 1995. 174 p. (Boletim Técnico, 5).

[39] USSEGLIO-TOMASSET, L. Chimica enológica. $4^{\mathrm{a}}$ ed. Brescia: AEB, 1995. 343 p.

[40] WEBB, A.D. Chemistry of winemaking. Washington: American Chemical Society, 1974., 311 p. 